$$
\begin{array}{ll}
\text { Report No. BMI-1170 } \\
\text { Metallurgy and Ceramics } \\
\text { (TID-4500, 12th Ed.) }
\end{array}
$$

Contract No. W-7405-eng-92

\title{
HIGH-TEMPERATURE OXIDATION AND CONTAMINATION OF NIOBIUM
}

\section{by}

William D. Klopp

Chester T. Sims

Robert I. Jaffee

February 19, 1957

BATTELLE MEMORIAL INSTITUTE

$505 \mathrm{King}$ Avenue

Columbus 1 , Ohio 


\section{DISCLAIMER}

This report was prepared as an account of work sponsored by an agency of the United States Government. Neither the United States Government nor any agency Thereof, nor any of their employees, makes any warranty, express or implied, or assumes any legal liability or responsibility for the accuracy, completeness, or usefulness of any information, apparatus, product, or process disclosed, or represents that its use would not infringe privately owned rights. Reference herein to any specific commercial product, process, or service by trade name, trademark, manufacturer, or otherwise does not necessarily constitute or imply its endorsement, recommendation, or favoring by the United States Government or any agency thereof. The views and opinions of authors expressed herein do not necessarily state or reflect those of the United States Government or any agency thereof. 


\section{DISCLAIMER}

Portions of this document may be illegible in electronic image products. Images are produced from the best available original document. 
Page

ABSTRACT . . . . . . . . . . . . . . . . . . . 1

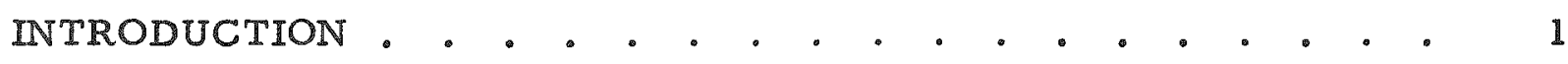

PAST WORK . . . . . . . . . . . . . . . . . . . 2

TEST PROCEDURES. • . . . . . . . . . . . . . . . 3

EXPERIMENTAL RESULTS • • . . . . • . . . . . . . 4

Reaction With Oxygen . . . . . . . . . . . . . . 4

Reaction With Nitrogen . . . . . . . . . . . . . . 9

Reaction With Air. . . . . . . . . . . . . . . . 9

Contamination Studies . . . . . . . . . . . . . 11

SUMMARY • . . . . . . . . . . . . . . . . . . . 21

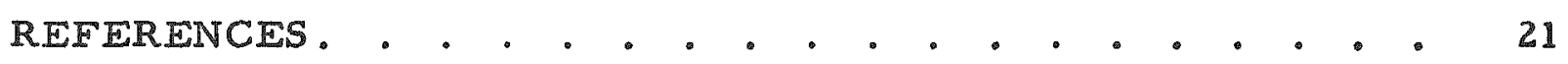




\section{1 \\ HIGH-IEMPERATURE OXIDATION AND \\ CONTAMINATION OF NIOBIUM}

William D. Klopp, Chester T. Sims, and Robert I. Jaffee

$[+11170$

The oxidation and contamination rates of niobium in oxygen and in air were measured in the temperature range 600 and $1200 \mathrm{C}$. The oxidation curves in oxygen were linear and the rate constants were correlated by an Arrhenius sype plot. The heat of reaction was 5,410 cal per mole from 600 to $1100 \mathrm{C}$; above $1100 \mathrm{C}$ the reactions were rapid and the rates could not be correlated to the Arrhenius-type plot. The activation energy for diffusion of oxygen in niobium was calculated from contamination data. Weight-change curves of niobium in air were also linear, with lower rates than in oxygen. The heat of reaction was, from the reaction rate data, 10,100 cal per mole from 600 to $1200 \mathrm{C}$. Contamination in air-reacted niobium was similar to that in oxygen-reacted niobium, suggesting that oxygen is the primary diffusing contaminant.

\section{INTRODUCTION}

Niobium metal and its alloys are receiving considerable attention as possible structural materials for jet engines and nuclear reactors. There are several reasons for this interest in addition to the stimulus of recent discoveries of extensive niobium ore reserves. Niobium possesses good strength and creep resistance at elevated temperatures. It also has a lowthermal-neutron-absorption cross section, 1.1 barns. The oxide of niobium is not volatile at the proposed service temperatures, offering possibilities for improved oxidation resistance by alloying.

Although niobium possesses only moderate strength at low temperatures, the strength does not fall off rapidly at elevated temperatures as for many other metals. In the range 1600 to $1800 \mathrm{~F}$, the rupture strength of niobium is comparable to that of molybdenum. For example, the 100-hr rupture strengths at $1600 \mathrm{~F}$ are about $20,000 \mathrm{psi}$ for niobium(1) and 15,000 to 30,000 psi for molybdenum(2), while at $1800 \mathrm{~F}$, 100-hr rupture strengths are 14,000 to 17,000 psi for niobium $(1,3)$ and 10,000 to 17,000 for molybdenum $(2)$. Thus, from a strength standpoint, niobium is quite attractive for high-temperature service.

The major shortcoming of niobium is its low resistance to oxidation at temperatures above several hundred Centigrade. The oxide formed is not volatile below about $1400 \mathrm{C}$ but apparently is not protective. To provide a base line for determining the effects of alloying elements on oxidation, a study was initiated on the oxidation and contamination of pure niobium. This

1) References at end of text. 
study is discussed here. The effect of alloying on the oxidation of niobium is discussed in a separate paper. (4)

\section{PAST WORK}

Brauer $(5)$ has reported that there are three stable niobium oxides, $\mathrm{Nb}_{2} \mathrm{O}_{5}, \mathrm{NbO}_{2}$, and $\mathrm{NbO}$. The most stable oxide, $\mathrm{Nb}_{2} \mathrm{O}_{5}$, is white or yellowwhite and exists in three modifications designated as low $(T)$, middle (M), and high temperature $(H)$. The $T$ form is stable up to $900 \mathrm{C}$, the $M$ form is stable between 1000 and $1100 \mathrm{C}$, and the $\mathrm{H}$ form is stable above $1100 \mathrm{C}$. The crystal structure of $\mathrm{Nb}_{2} \mathrm{O}_{5}$ is reported to be isomorphous with $\mathrm{Ta}_{2} \mathrm{O}_{5}$, which is pseudohexagonal orthorhombic $(6)$.

$\mathrm{NbO}_{2}$ has a rutile-type structure, with a $=4.84 \mathrm{~A}, \mathrm{c}=2.99 \mathrm{~A}$, and $c / a=0.618$. This oxide can be formed as a black powder by reduction of $\mathrm{Nb}_{2} \mathrm{O}_{5}$ with hydrogen or niobium metal powder. NbO forms a cubic structure with a $4.203 \mathrm{~A}$.

The oxidation of niobium has been studied previously by Gulbransen and Andrew $(7)$ and by Inouye(8). Gulbransen and Andrew investigated the reaction of niobium with oxygen at a pressure of $7.6 \mathrm{~cm}$ mercury by the constant weighing method, using a microbalance. They reported parabolic reaction curves at 250 and $375 \mathrm{C}$ with an activation energy of $22,800 \mathrm{cal}$ per mole. A thin oxide film assumed to be $\mathrm{NbO}$ was formed at these temperatures. The same authors also investigated the reaction of niobium with nitrogen over the range 400 to $800 \mathrm{C}$. These reaction curves also followed the parabolic rate law, with an activation energy of 25,400 cal per mole. Reaction with nitrogen was much slower than reaction with oxygen and no surface film was visible on the nitrided samples.

Inouye measured the rates of reaction between niobium and wet and dry air in the range 400 to $1200 \mathrm{C}$ by a constant weighing method. This investigator reported a transition from parabolic to linear reaction after $21-\mathrm{hr}$ ex posure at $400 \mathrm{C}$ and linear reaction curves in the range 600 to $1200 \mathrm{C}$. The effects of moisture varied at different temperatures, increasing the rate of reaction at $400 \mathrm{C}$, decreasing the rate at $600 \mathrm{C}$, but having very little effect at $800 \mathrm{C}$ or higher. Differences in reaction rates were observed at 1000 .and $1200 \mathrm{C}$ between sheet and rod samples, the rods having a higher oxidation rate. The activation energies were $13,400 \mathrm{cal}$ per mole in the temperature range 600 to $900 \mathrm{C}$ and $4,350 \mathrm{cal}$ per mole in the temperature range 900 to $1200 \mathrm{C}$. Oxide scales at all temperatures were identified by $X-r a y$ diffraction measurements as one or more of the $\mathrm{Nb}_{2} \mathrm{O}_{5}$ modifications. 


\section{TEST PROCEDURES}

In the present work reactions of niobium with oxygen and air were investigated in the temperature range of 600 to $1200 \mathrm{C}$.

The niobium-oxygen reaction rates were determined manometrically in a modified Sieverts apparatus described previously by Belle and Mallett (9). Cylinders machined from arc-melted buttons were used in these tests. The cylinders were induction heated in vacuum to the desired temperature before admitting oxygen. The oxygen was obtained from thermal decomposition of high-purity $\mathrm{KMnO}_{4}$ and was dried before entering the reaction chamber by passing through a dry ice-acetone cold trap.

The reactions in air were measured by intermittent weighing of the samples after 1, 5, and 10-hr exposure to undried air in small muffle furnaces. The samples consisted of either 0.1 by 0.2 by 0.45 -in. slabs cut from arc-melted ingots or 0.25 -in.-diameter rod swaged from doublevacuum-sintered niobium. Melting stock for the arc-melted ingots was cut from commercial rolled niobium sheet. The hardnesses of the cast ingots ranged from 110 to 130 VHN. This compared favorably with the hardness of the sheet melting stock ( $110 \mathrm{VHN}$ ) and indicates that very little contamination occurred during arc melting. Representative analyses of these materials indicate the presence of about $0.1 \mathrm{w} / 0$ oxygen, $0.05 \mathrm{w} / 0$ nitrogen, and $0.03 \mathrm{w} / 0$ carbon. Prior to air exposure, all samples were polished on $600 \mathrm{mg}$ it emery paper and degreased in acetone. The samples were placed in cleaned and prefired shallow porcelain crucibles for exposure. Weight gains were determined with a sensitivity of better than $0.1 \mathrm{mg}$ per square centimeter.

Tests were also performed in a nitrogen atmosphere in the modified Sieverts apparatus. Matheson prepurified nitrogen, which has a purity of better than 99.99 per cent, was used. It was dried in a dry ice acetone coldtrap before entering the reaction chamber.

Knoop hardness traverses were made on each of the reacted samples to determine the effects of temperature and gas composition on the contamination hardening. Two or four traverses were made on each sample and averaged to give one hardness curve. The depth of contamination was expressed as the distance from the final metal surface to the point $50 \mathrm{Knoop}$ points harder than the uncontaminated metal. Diffusion coefficients also were calculated from each of the contamination curves. 
EXPERIMENTAL RESULTS

Reaction With Oxygen

The reaction of niobium with pure oxygen between 600 and $1200 \mathrm{C}$ is shown graphically in Figure 1 , with reaction rate data given in Table 1 . As seen in Figure 1, the reactions at 600 to $1000 \mathrm{C}$ proceeded linearly (within the range of experimental error) after slight deviations at the beginning of oxidation. At $1100 \mathrm{C}$, the rate increased sharply after 80 min oxidation to approximately the same rate as observed on the 1150 and $1200 \mathrm{C}$ reaction curves. This may be due to a change in the rate-determining mechanism to the same one which controls the oxidation at 1150 and $1200 \mathrm{C}$. The reactions above $1100 \mathrm{C}$ had much higher rates than would be expected from the lower temperature behavior.

At lower temperatures, the outer scale was white and powdery, while at highex temperatures, it formed as slabs. X-ray diffraction patterns made on the outer scales from the samples reacted at 600 and $1000 \mathrm{C}$ showed these scales to be $\mathrm{T}$ type and $\mathrm{M}$ type $\mathrm{Nb}_{2} \mathrm{O}_{5}$, respectively. A thin, black, adherent subscale was present on the surfaces of the reacted metal samples. This film was identified by $\mathrm{X}$-ray diffraction as a mixture of oriented $\mathrm{Nb}_{2} \mathrm{O}_{5}$ and $\mathrm{NbO}$. No $\mathrm{NbO}_{2}$ was found in either the outer scale or the subscale.

One test was conducted in oxygen at $1400 \mathrm{C}$, but the reaction was exo. thermic and the sample quickly overheated and melted. This temperature is near the reported melting point of $\mathrm{Nb}_{2} \mathrm{O}_{5}$, which is $1440 \mathrm{C}$. (10)

The Arrhenius-type plot of reaction rates versus temperature, Figure 2, shows that the reaction rates are consistent and have a linear $\log \mathrm{k}$ versus $1 / \mathrm{T}$ relationship in the range 600 to $1100 \mathrm{C}$. The activation energy for the reaction in this range is 5,410 cal per mole. An inflection occurs in this curve between 1100 and $1150 \mathrm{C}$. At this point, the reaction rate increases with temperature at a much higher rate than at the lower temperatures. This indicates a change in the rate-determining mechanism, although there was no visual difference in the type of scale formed.

The effects of oxygen pressure on the niobium-oxygen reaction were investigated at $800 \mathrm{C}$. Tests were conducted at 76,38 , and $7.6 \mathrm{~cm}$ oxygen pressure. Results are shown in Figure 3. At $76 \mathrm{~cm}$ pressure, a linear reaction curve was obtained with a rate constant of $0.50 \mathrm{ml} \mathrm{O}_{2} /\left(\mathrm{cm}^{2}\right)(\mathrm{min})$. At $38 \mathrm{~cm}$ oxygen pressure, the reaction was slower, becoming linear after about $40 \mathrm{~min}$ with a rate constant of $\left.0.272 \mathrm{ml} \mathrm{O} / / \mathrm{cm}^{2}\right)(\mathrm{min})$. However, at $7.6 \mathrm{~cm}$ oxygen pressure, the curve was parabolic and less oxygen was consumed than at $38 \mathrm{~cm}$ oxygen pressure.

Examination of the oxidized samples revealed that the nature of the scales also changed with decreasing oxygen pressure. At $76 \mathrm{~cm}$ oxygen 
TABLE 1. OXIDATION AND CONTAMINATION DATA FOR NIOBIUM=OXYGEN REACTION

\begin{tabular}{|c|c|c|c|c|c|c|}
\hline \multicolumn{3}{|c|}{ Oxidation Conditions } & \multirow[b]{2}{*}{$\begin{array}{c}\text { Time } \\
\text { low }\end{array}$} & \multirow{2}{*}{$\begin{array}{c}\text { Oxidation } \\
\text { Rate Constant } \\
\mathrm{g} /\left(\mathrm{cm}^{2}\right)(\mathrm{sec}) \text { or } \\
\mathrm{g}^{2} /\left(\mathrm{cm}^{4}\right)(\mathrm{sec})\end{array}$} & \multirow{2}{*}{$\begin{array}{c}\text { Depth of } \\
\text { Contamination(a), } \\
\mathrm{cm}\end{array}$} & \multirow[b]{2}{*}{$\begin{array}{c}\text { Diffusion Rate, } \\
\mathrm{cm}^{2} \text { per sec } \\
\end{array}$} \\
\hline $\begin{array}{c}\text { Temperature. } \\
\mathrm{C} \\
\end{array}$ & $\begin{array}{l}\text { Pressure, } \\
\mathrm{cm} \text { mercury }\end{array}$ & $\begin{array}{c}\text { Time, } \\
\text { hr }\end{array}$ & & & & \\
\hline 600 & 76 & 2.30 & Linear & $6.5 \times 10^{-6}$ & 0.010 & $3.66 \times 10^{-9}$ \\
\hline 800 & 76 & 1.30 & Linear & $11.9 \times 10^{-6}$ & 0.028 & $3.65 \times 10^{-8}$ \\
\hline 1000 & 76 & 1.62 & Linear & $17.5 \times 10^{-6}$ & 0.076 & $1.25 \times 10^{-7}$ \\
\hline 1100 & 76 & 1.50 & Linear & $20.2 \times 10^{-6}$ & 0.140 & $6.34 \times 10^{-7}$ \\
\hline 1150 & 76 & 0.68 & Lineas & $78.9 \times 10^{-6}$ & 0.111 & $7.86 \times 10^{-7}$ \\
\hline 1200 & 76 & 1.00 & Linear & $72.5 \times 10^{-6}$ & 0.155 & $6.37 \times 10^{-7}$ \\
\hline 800 & 7.6 & 1.50 & Parabolic & $2.78 \times 10^{-7}$ & 0.028 & $3.73 \times 10^{-8}$ \\
\hline 800 & 38 & 1.50 & Linear & $6.47 \times 10^{-6} 6$ & 0.033 & $3.84 \times 10^{-8}$ \\
\hline
\end{tabular}

(a) The depth of contamination was determined as the point on the hardness versus depth curve which was $50 \mathrm{KHN}$ above the hardness of the uncontaminated metal. 


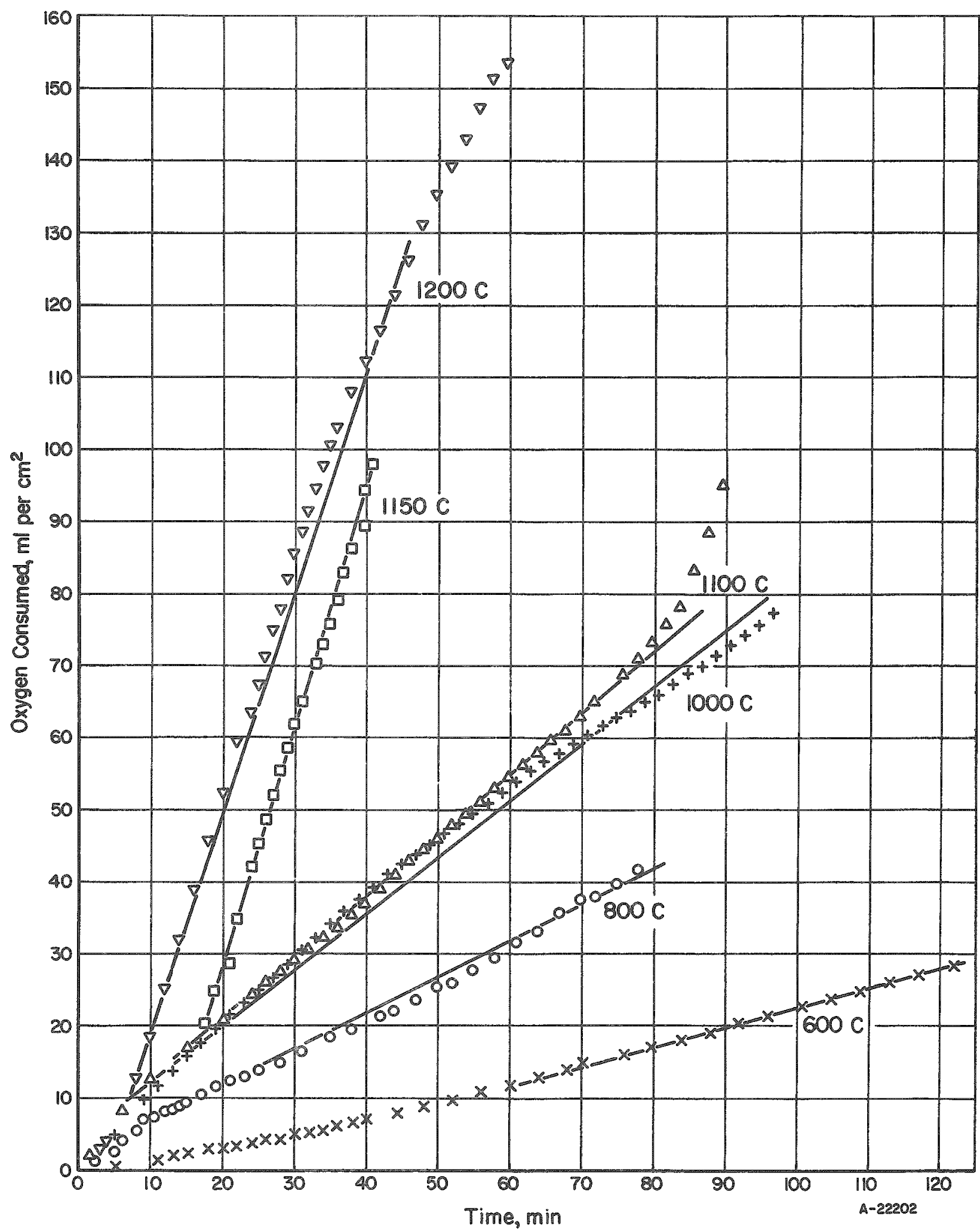

FICURE I. REACTION OF NIOBIUM WITH OXYGENAT VARIOUS TEMPERATURES 


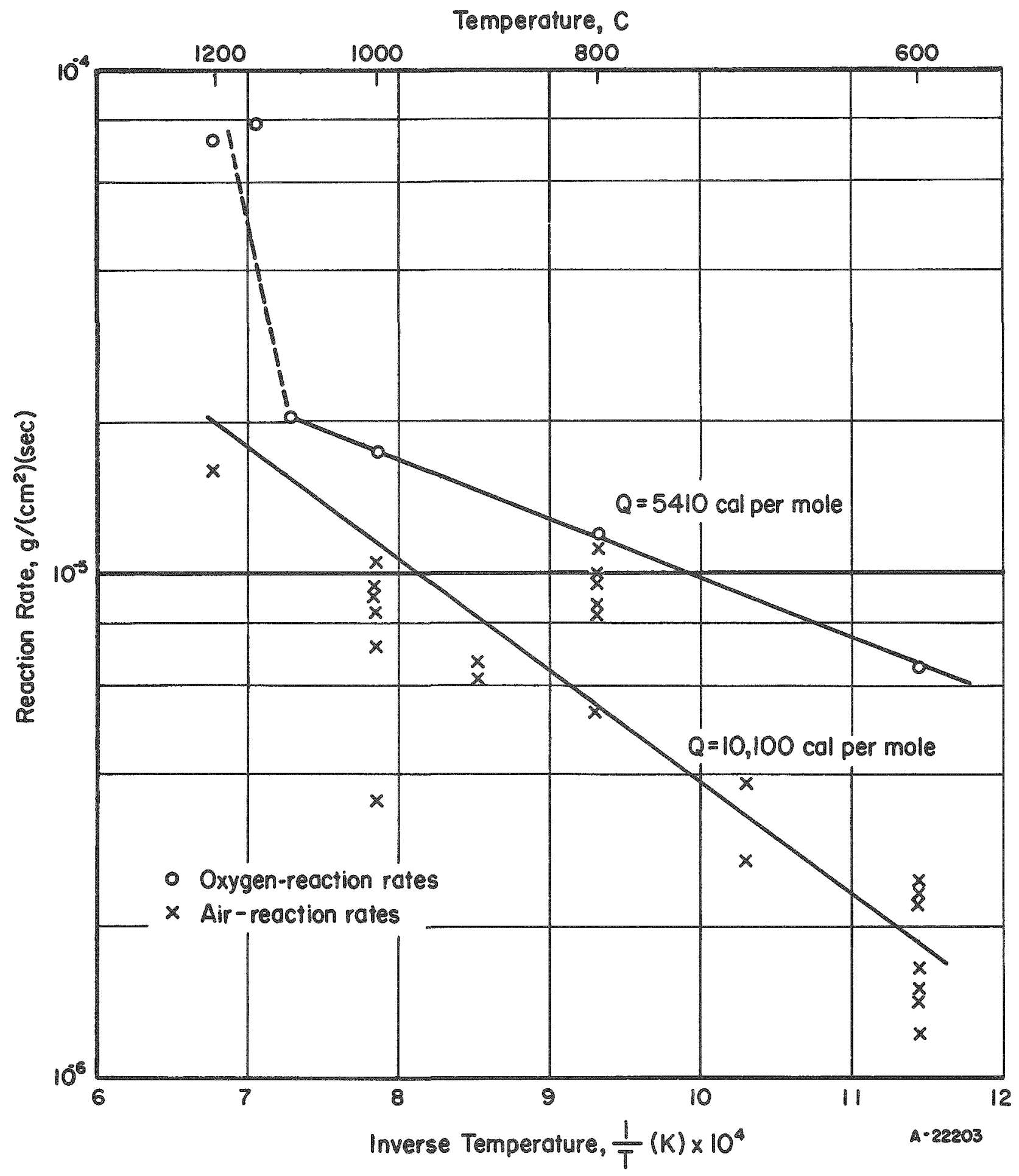

FIGURE 2. DEPENDENCE OF NIOBIUM-OXY GEN AND NIOBIUMAIR REACTION RATES ON TEMPERATURE 


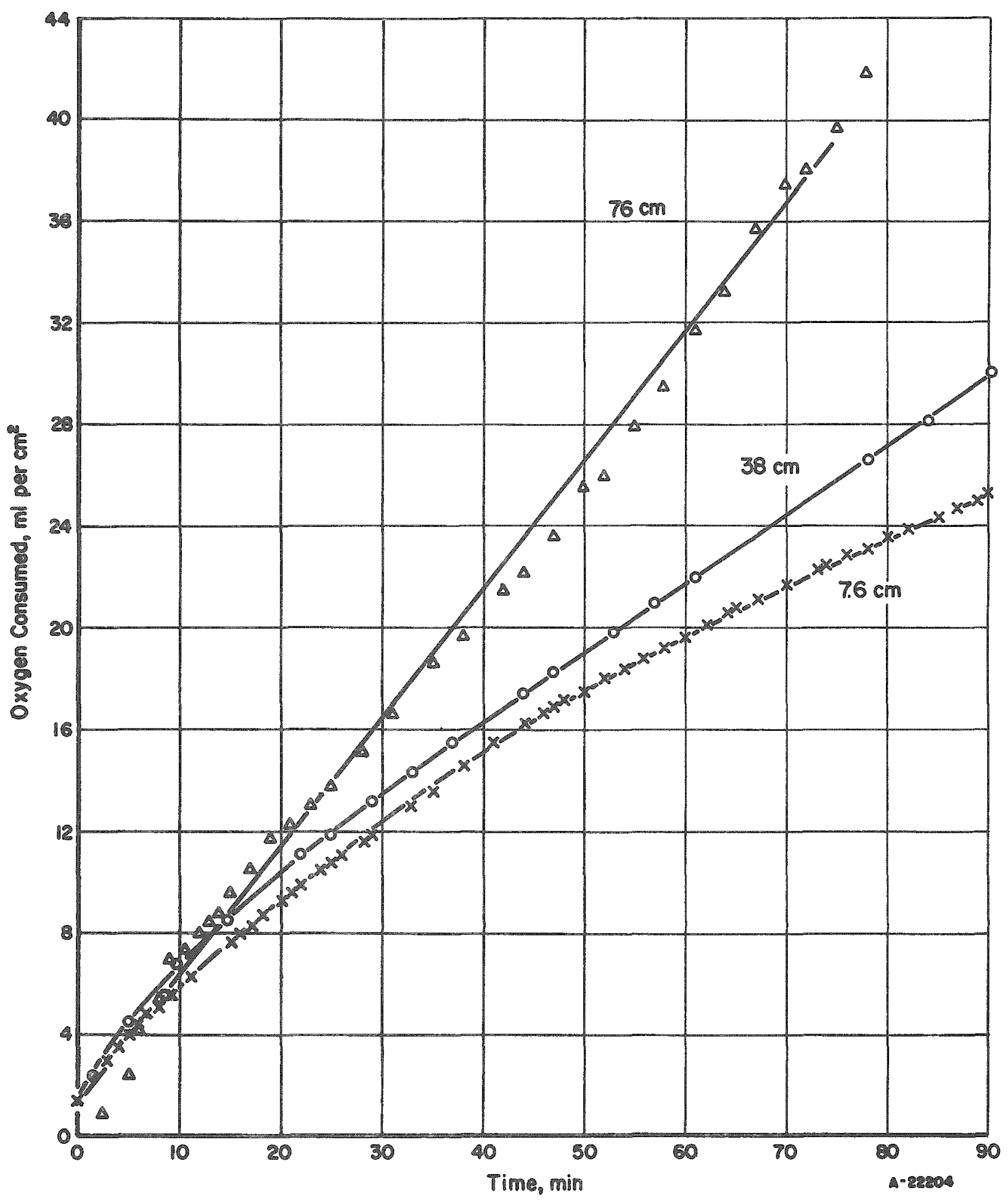

FIGURE 3. EFFECT OF PRESSURE ON NIOBIUM-OXYGEN REACTION RATE AT $800 \mathrm{C}$ 
pressure the scale was composed primarily of white $\mathrm{Nb}_{2} \mathrm{O}_{5}$ with a very thin black subscale on the metal surface. As the oxygen pressure was decreased, the thickness of the $\mathrm{Nb}_{2} \mathrm{O}_{5}$ layer decreased and the thickness of the black subscale appeared to increase. $X$-ray diffraction measurements showed the outer scale to be $\mathrm{T}$-type (low temperature) $\mathrm{Nb}_{2} \mathrm{O}_{5}$ and the subscale to be a mixture of oriented $\mathrm{T}$-type $\mathrm{Nb}_{2} \mathrm{O}_{5}$ and $\mathrm{NbO}$. There were no traces of $\mathrm{NbO}_{2}$, the intermediate oxide, in the scale.

Attempts were made to correlate the thickness of the adherent subscale with the reaction $x$ ates at the various pressures, but the results were inconclusive. However, it is apparent that one of the reactants must diffuse through this subscale during oxidation, the rate of diffusion depending perhaps on the electrical conductivity of the subscale. This provides a mechanism by which alloying elements can reduce the over-all oxidation rate, i.e., by decreasing the conductivity of the subscale. Additional experiments are being conducted to determine the rate-controlling reaction.

Reaction With Nitrogen

A niobium cylinder, approximately 0.45 in. long by 0.30 in. in diameter, was heated in an atmosphere of pure nitrogen in the modified Sieverts apparatus and the consumption of gas measured by the change in pressure. The sample was held at $800 \mathrm{C}$ for $50 \mathrm{~min}$, after which the temperature was raised to $1000 \mathrm{C}$ for $18 \mathrm{~min}$. No reaction could be detected at either of these temperatures, although a faint tarnish film was present on the sample at the

conclusion of the test. Previous tests by Gulbransen and Andrew $(7)_{\text {indi- }}$ cated that the reaction between niobium and nitrogen follows the parabolic law in the range 400 to $800 \mathrm{C}$ and is very slow. From the data of Gulbransen and Andrew, the total amount of nitrogen reacted during the test described was estimated to be $9 \times 10^{-10} \mathrm{~g}$ or $0.3 \mathrm{ml}$ of nitrogen. This small amount is near the detection limit of the modified Sieverts apparatus. No additional tests were conducted in nitrogen.

\section{Reaction With Air}

As discussed previously, air oxidation tests were conducted by an intermittent weighing method. This method is most expedient but cannot be used to determine the time-dependent nature of the reaction curve. Based on the fact that niobium reacts with pure oxygen in a linear manner and that the scales formed in air were loose and apparently nonprotective, linear oxidation rate has been as sumed for the reaction of niobium with air.

Seven series of tests were conducted in the range 600 to $1200 \mathrm{C}$. Photographs of representative samples after oxidation are shown in Figure 4. 
Time,

Temperature, $\mathrm{C}$

hr

600

800

1000

1

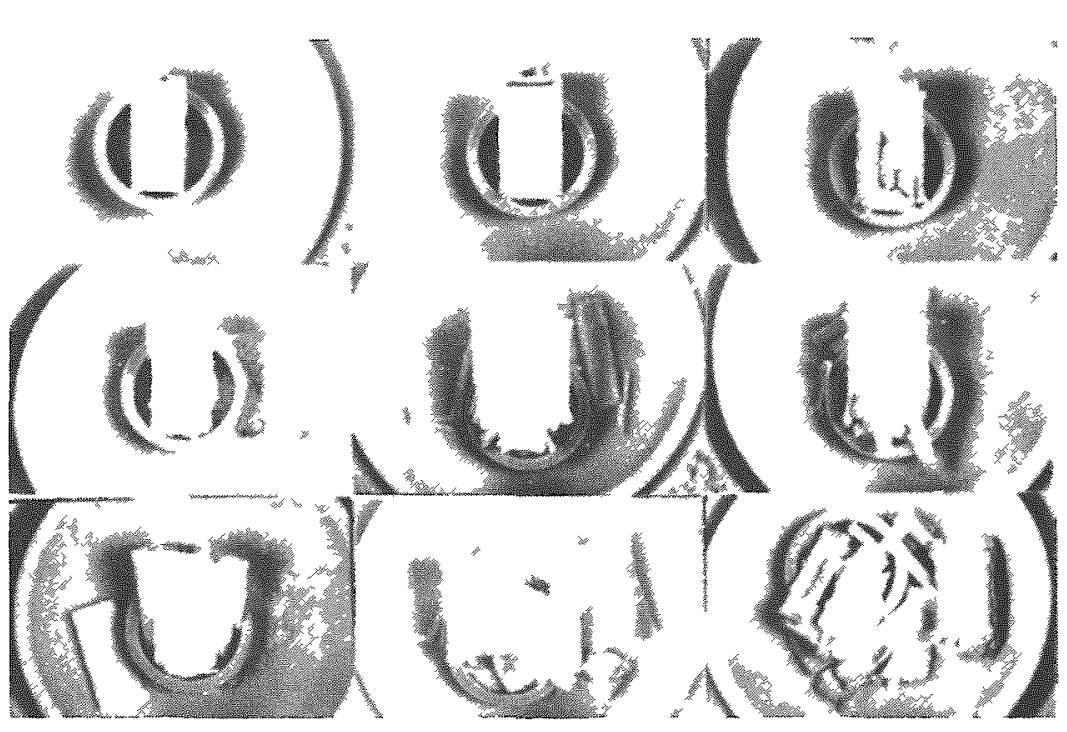

FIGURE 4. AIR OXIDATION OF CAST NIOBIUM FOR VARIOUS TIMES AT 600, 800, AND $1000 \mathrm{C}$ 
The average oxidation rates, given in Table 2, are lower than those found for oxygen. This is apparently the result of the lower oxygen content in aix.

In all of these tests, with the exception of $\mathrm{Nb}-4$, the oxidation rate at $800 \mathrm{C}$ was higher than at $1000 \mathrm{C}$. The exact cause of this behavior is not known, but it could be caused by geometry of the test specimens, moisture content of the oxidizing atmosphere, or sintering of the scale at the higher temperature. Data of Inouye(8) at $1000 \mathrm{C}$ indicate a range of oxidation rates varying by a factor of 2 as the shape of the specimen is changed from sheet to rod. The effect of moisture has not yet been clearly indicated and more work remains to be done on this aspect. Sintering of the scale may be a factor in slowing oxidation at $1000 \mathrm{C}$ by preventing ready access of oxygen to the metal-oxide interface. Sintering was indicated since the scales tend to form in slabs at the high temperatures, whereas they were powdery at the low temperatures.

One series of four samples, $\mathrm{Nb}-4$, was painted on one side with a paste of $\mathrm{Cr}_{2} \mathrm{O}_{3}$ and methanol before oxidizing. After exposing for $2 \mathrm{hr}$ at $600,800,1000$, and $1200 \mathrm{C}$, the samples were remexamined. It was found that the $\mathrm{Cr}_{2} \mathrm{O}_{3}$ was on the outside surface of the oxide in all four cases. This experiment indicates that the gas-metal reaction occurs at the metalscale interface, as would be expected in the case of a metal which oxidizes linearly. Oxygen must diffuse through the oxide scale either atomically or molecularly by means of holes or cracks to reach the reaction zone in this type of oxidation.

Two series of tests were conducted on rod which had been swaged from a double-sintered 1/2 by 1/2-in. niobium powder metallurgy bar.

One series, $\mathrm{Nb}-7$, was run on the as-swaged rod; the other series, $\mathrm{Nb}-6$, was conducted on the same rod vacuum annealed $1 / 2 \mathrm{hr}$ at $2150 \mathrm{C}$. Although small variations were noted in the oxidation rates of the two materials at individual temperatures, no consistent difference was apparent in the over-all oxidation behavior in the two conditions.

An Arrhenius plot of the air-oxidation rates is shown in Figure 2. An activation energy of $10,100 \mathrm{cal}$ per mole was calculated from this plot, although the large amount of scatter in the data makes this value uncertain. This value is higher than the activation energy for the niobium-oxygen reaction, which was 5,410 cal per mole. Inouye $(8)$ reported an activation energy of 13,400 cal per mole for the reaction between niobium and dry air in the range 600 to $900 \mathrm{C}$, and $4,350 \mathrm{cal}$ per mole in the range 900 to $1200 \mathrm{C}$.

Contamination Studies

The contamination of niobium by oxygen, nitrogen, and air was studied by hardness traverses of the unreacted metal cores after exposure. Several 
TABLE 2. OXIDATION DATA FOR NIOBIUM AIR REACTION

\begin{tabular}{|c|c|c|c|c|c|c|c|c|}
\hline \multirow{2}{*}{$\begin{array}{l}\text { Test } \\
\text { Series }\end{array}$} & \multirow{2}{*}{$\begin{array}{l}\text { Condition } \\
\text { and Shape(a) }\end{array}$} & \multirow{2}{*}{$\begin{array}{l}\text { Exposure } \\
\text { Time, hr }\end{array}$} & \multicolumn{6}{|c|}{$\begin{array}{c}\text { Oxidation Rate, } 10^{-6} \mathrm{~g} /\left(\mathrm{cm}^{2}\right)(\mathrm{sec}) \text {. } \\
\text { at Indicated Temperatures }\end{array}$} \\
\hline & & & $600 \mathrm{C}$ & $700 \mathrm{C}$ & $800 \mathrm{C}$ & $900 \mathrm{C}$ & $1000 \mathrm{C}$ & $1200 \mathrm{C}$ \\
\hline $\mathrm{Nb}-1$ & Cast slab & 1 & 1.39 & $=\infty$ & 9.05 & $-\infty$ & 7.08 & $-\infty$ \\
\hline $\mathrm{Nb}-2$ & Cast slab & 5 & 1.50 & $=$ & 8.55 & $\infty$ & 7.17 & $\infty$ \\
\hline $\mathrm{Nb}=3$ & Cast slab & 10 & 2.22 & $m$ & 10.0 & $-\infty$ & 3.56 & $-\infty$ \\
\hline $\mathrm{Nb}-4$ & Cast slab(b) & 2 & 1.64 & $-\infty$ & 5.33 & $-\infty$ & 10.7 & 16.0 \\
\hline $\mathrm{NB}-5$ & Cast rod & 5 & 1.22 & $\infty$ & 9.85 & $-\infty$ & 9.11 & $\infty$ \\
\hline $\mathrm{Nb}-6$ & Annealed rod(c) & 5 & 2.31 & 3.86 & 8.66 & 6.17 & 8.45 & $=-\infty$ \\
\hline $\mathrm{Nb}-7$ & Wrought rod & 5 & 2.20 & 2.69 & 11.1 & 6.66 & 9.42 & $\infty$ \\
\hline
\end{tabular}

(a) Slab dimensions, 0.1 by 0.2 by 0.45 in, rod dimensions, $0.3-i n_{0}$ diameter by 0.45 in. long. All specimens labeled "cast" were machined from arc melted buttons.

(b) One side painted with $\mathrm{Cr}_{2} \mathrm{O}_{3}$ for marker experiment.

(c) Annealed $1 / 2$ hr at $2150 \mathrm{C}$ in vacuum. 
13

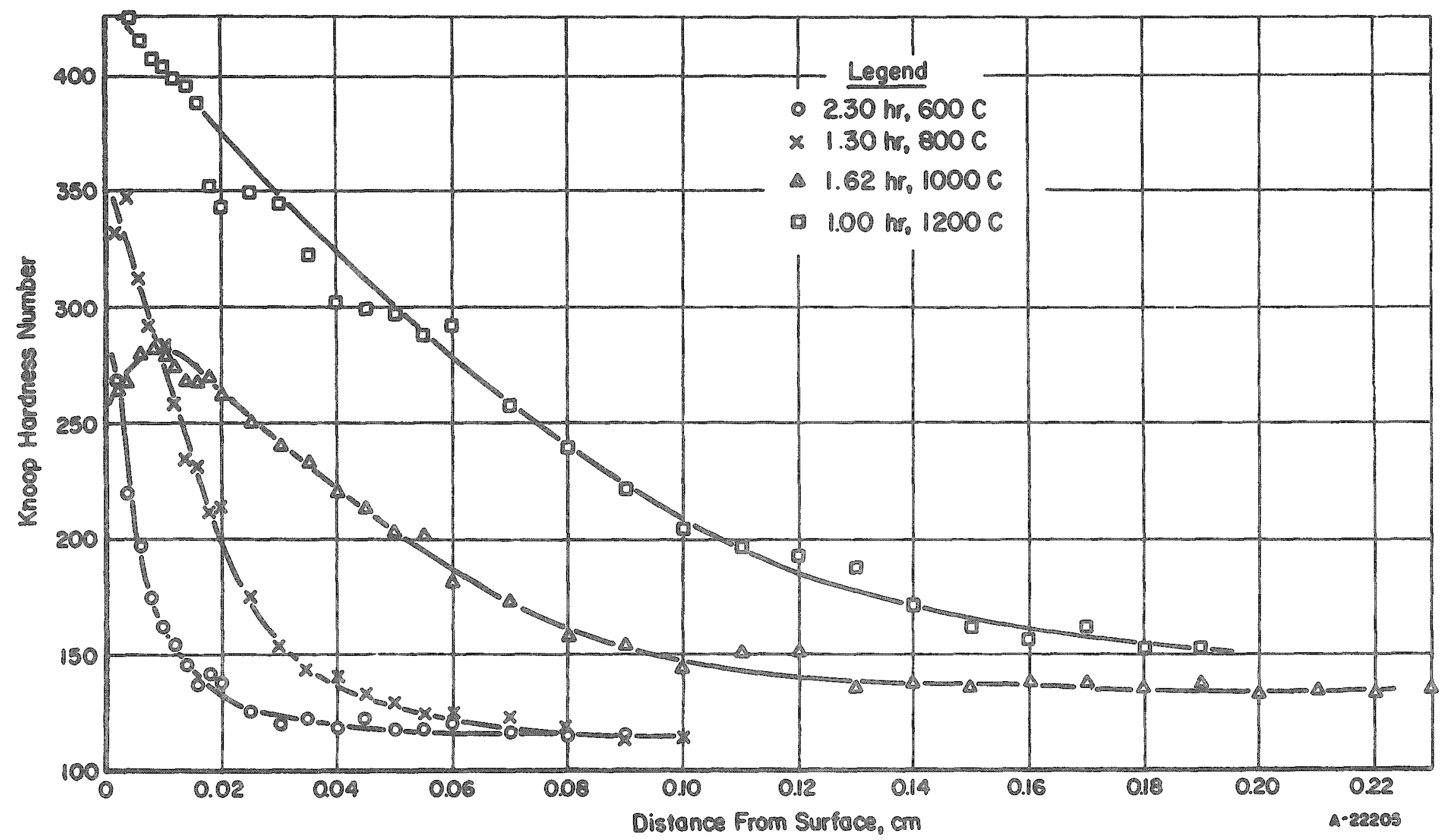

FIGURE 5. CONTAMINATION HARDENING OF NIOBIUM BY OXYGEN AT VARIOUS TEMPERATURES 
hardness traverses were made on each sample and averaged to give contam ination curves. The contamination curves for niobium exposed to oxygen in the range 600 to $1200 \mathrm{C}$ axe shown in Figure 5. The contamination curve for niobium exposed to nitrogen at 800 and $1000 \mathrm{C}$ is shown in Figure 6 . Curves from the air-oxidized samples were similar to those from the oxygenreacted samples.

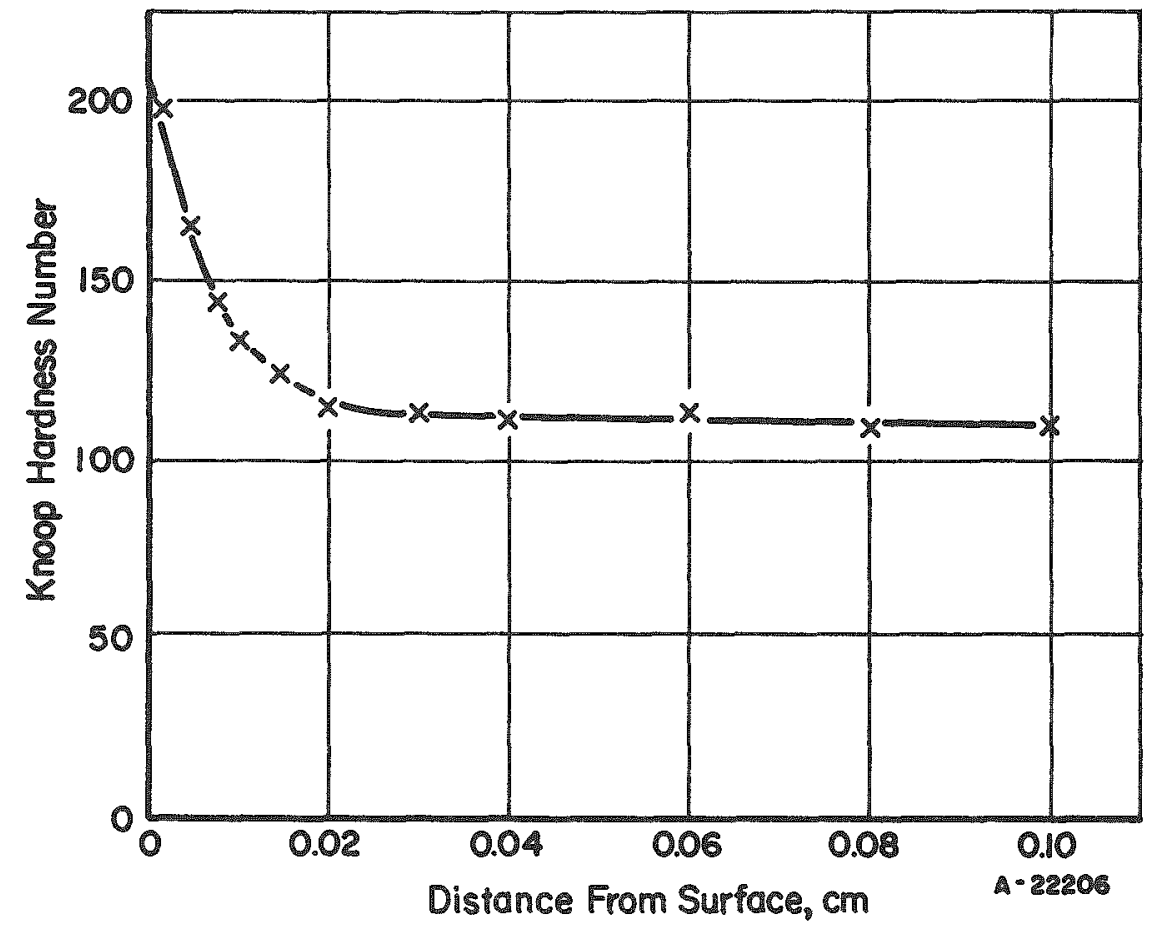

FIGURE 6. CONTAMINATION HARDENING OF NIOBIUM BY NITROGEN AFTER $50 \mathrm{MIN}$ AT $800 \mathrm{C}$ AND 18 MTN AT $100 \mathrm{C}$

The depth of contamination, expressed as the distance from the final metal surface to the point on the hardness-traverse curve which was 50 points harder than the base metal, was measured from these curves for the oxygenreacted and air-reacted samples. These data are given in Tables 1 and 3 .

No quantitative measurements were made on the sample reacted with nitrogen, since it was exposed at two different temperatures. However, it is evident from comparison of the contamination curves that nitrogen contamination is much less severe than oxygen contamination.

The diffusion coefficients associated with the contamination process were calculated from the contamination curves of the oxygen-reacted and air-reacted samples.

The method for the calculation of $D$ involved use of the Van OstrandDewey solution(11) to Fick's second law of diffusion. This law states that the rate of accumulation of a diffusing element in a diffusion medium is 
TABLE 3. CONTAMINA TION DATA FOR AIR-OXIDIZED NIOBIUM

\begin{tabular}{|c|c|c|c|c|}
\hline \multirow[b]{2}{*}{$\begin{array}{l}\text { Test } \\
\text { Series }\end{array}$} & \multicolumn{2}{|c|}{ Oxidation Conditions } & \multirow{2}{*}{$\begin{array}{l}\text { Depth of } \\
\text { Contamination } \\
\text { cm(a) }\end{array}$} & \multirow[b]{2}{*}{$\begin{array}{l}\text { Diffusion Rate, } \\
\mathrm{cm}^{2} \text { per sec }\end{array}$} \\
\hline & $\begin{array}{c}\text { Time, } \\
\text { hr }\end{array}$ & $\begin{array}{c}\text { Temperature, } \\
\mathrm{C}\end{array}$ & & \\
\hline \multirow[t]{3}{*}{$\mathrm{Nb}-1$} & 1 & 600 & 0.006 & $2.35 \times 10^{=0} 9$ \\
\hline & & 800 & 0.032 & $6.44 \times 10^{-8}$ \\
\hline & & 1000 & 0.067 & $1.30 \times 10^{-7}$ \\
\hline \multirow[t]{3}{*}{$\mathrm{Nb}=2$} & 5 & 600 & 0.013 & $2.87 \times 10^{-9}$ \\
\hline & & 800 & 0.049 & $4.06 \times 10^{-8}$ \\
\hline & & 1000 & $>0.12$ & $1.74 \times 10^{-7} 7$ \\
\hline \multirow[t]{3}{*}{$N b=3$} & 10 & 600 & 0.013 & $1.70 \times 10^{-9}$ \\
\hline & & 800 & $-\infty(b)$ & $-\infty$ \\
\hline & & 1000 & $>0.1$ & $\infty$ \\
\hline \multirow[t]{3}{*}{$\mathrm{Nb}-5$} & 5 & 600 & 0.012 & $2.95 \times 10^{-9}$ \\
\hline & & 800 & 0.049 & $3.50 \times 10^{-8}$ \\
\hline & & 1000 & 0.115 & $1.63 \times 10^{-7}$ \\
\hline
\end{tabular}

(a) The depth of contamination was taken as the point on the hardness-versus-depth curve which was $50 \mathrm{KHN}$ above the hardness of the uncontaminated metal.

(b) Sample was completely oxidized. 
equal to the difference between the inward and outward diffusion Ilux. Stated mathematically, Fick's second law is:

$$
\frac{\partial c}{\partial t}=\frac{D \partial^{2} c}{\partial x^{2}}
$$

where:

$$
\begin{aligned}
& D=\text { diffusion coefficient }\left(\mathrm{cm}^{2}\right. \text { per sec) } \\
& t=\text { time }(\mathrm{sec}) \\
& c=\text { concentration of the diffusing element } \\
& x=\text { distance from the boundary }(\mathrm{cm}) .
\end{aligned}
$$

The solution to Fick's second law for boundary conditions as met in the present work has been published previously by Van Ostrand and Dewey. (11) Their solution involves the probability (or error) function, and may be written as:

$$
\frac{c-c_{0}}{c_{m}-c_{0}}=1-\phi\left(\frac{x}{2 \sqrt{D t}}\right)
$$

where:

$$
\begin{aligned}
& c= \text { concentration of the diffusing element at a given distance } \\
& \text { from the surface } \\
& c_{0}= \text { original concentration of the diffusing element in the } \\
& \text { diffusion medium } \\
& c_{m}= \text { concentration of the diffusing element at the surface } \\
& \phi= \text { probability (or error) function } \\
& x, D, \text { and } t \text { are the same as in Equation }(1) .
\end{aligned}
$$

Assuming that the concentration of oxygen in niobium can be expressed in terms of hardness (H), Equation (2) can be rewritten as:

$$
\frac{H_{m}-H}{H_{m}-H_{0}}=\phi\left(\frac{x}{2 \sqrt{D t}}\right)
$$


Solving for $D$, the following equation is obtained:

$$
D=\frac{x^{2}}{4\left(\phi^{-1}\left[\frac{H_{m}-H}{H_{m}-H_{0}}\right]\right)^{2} t}
$$

where the term $\phi^{-1}\left[\frac{H_{m}-H}{H_{m}-H_{0}}\right]$ is the inverse error function of the hardness ratio.

Several assumptions were made in calculating $D$ by use of Equation (4), which may be sources of errors. These assumptions were:

(1) The diffusivity is assumed not to vary with concentration.

(2) The hardness of niobium is assumed to vary linearly with the concentration of oxygen in niobium.

(3) The initial niobium-niobium oxide boundary is assumed to be constant, while actually it is progressing inward as oxidation proceeds.

(4) The maximum hardnes, $H_{m}$ is assumed to increase with temperature, since the solubility of oxygen in niobium is known to increase with temperature. (12) The values of $\mathrm{H}_{\mathrm{m}}$, estimated from the experimental data, were taken as $400,450,500$, and $550 \mathrm{KHN}$ at $600,800,1000$, and $1200 \mathrm{C}$, respectively. Values for $H_{0}$ were actual experimental values, and ranged from 105 to 180 .

Three calculations were made for the diffusion coefficient from each of the contamination curves obtained from the oxygen-reacted and air-reacted samples. These coefficients were averaged to give one diffusion coefficient for each sample. The values of the diffusion coefficients so calculated are given in Table 1 for the oxygen-reacted samples and in Table 3 for the airreacted samples.

It is of interest to note that the diffusion coefficients for contamination are similar for the samples reacted at $800 \mathrm{C}$ at different oxygen pressures. The significance of this observation is that oxygen does not have free access to the bare metal surface after the beginning of oxidation. There is instead an impervious oxide layer of fixed oxygen content at the metal surface which supplies the oxygen which diffuses into the metal. This layer is the thin black subscale, which was described previously to consist of $\mathrm{NbO}$ and oriented $\mathrm{Nb}_{2} \mathrm{O}_{5}$. 


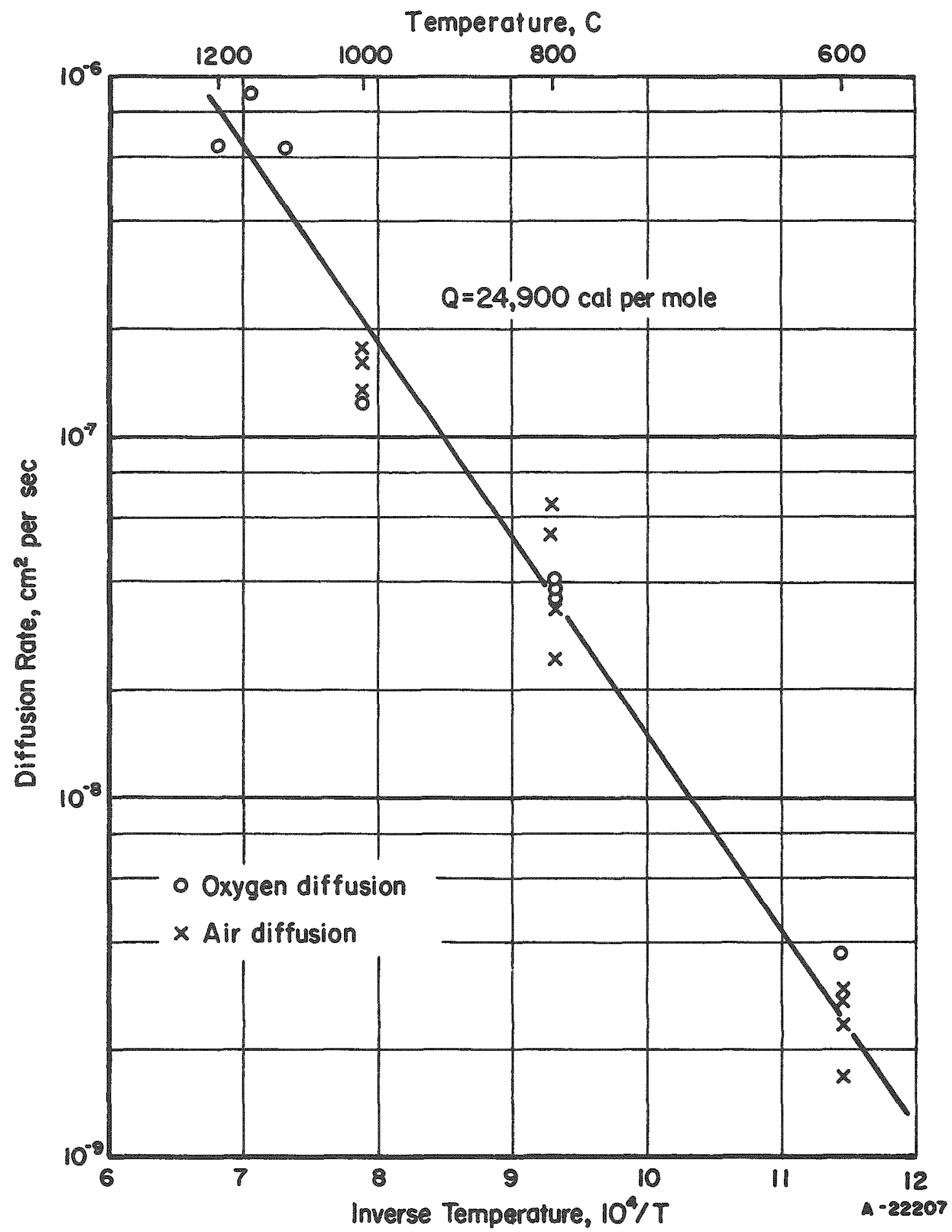

FIGURE 7. DEPENDENCE OF DIFIUSION RATES ON TEMPERATURE FOR FOR CONTAMINATION OF NIOBIUM IN OXYGEN AND IN AIR 
Comparison of the diffusion cosficients for oxygen-contamination and air-contamination shows that they are quite similar, indicating that oxygen is the primary contaminating gas in the air-contamination process. This is substantiated by the presence of the thin black subscale on the air-reacted samples and the fact that nitrogen reacts with and diffuses into niobium much more slowly than oxygen.

Accordingly, the contamination data and diffusion coefficients from both the oxygen-reacted and air-reacted samples have been averaged to calculate the diffusivity of oxygen in niobium. An Arrhenius-type plot of the diffusion coefficients from the oxygen-reacted and air-reacted samples is shown in Figure 7 . Values for $D, D_{0}$, and $Q$ were calculated from this plot and are given below:

$$
\begin{aligned}
D, 600 \mathrm{C} & \approx 2.4 \times 10^{-9} \mathrm{~cm}^{2} \text { per sec } \\
D, 800 \mathrm{C} & =3.5 \times 10^{-8} \mathrm{~cm}^{2} \text { per sec } \\
\text { D, } 1000 \mathrm{C} & \approx 2.1 \times 10^{-7} \mathrm{~cm}^{2} \text { per sec } \\
D_{0} & =4.07 \times 10^{-3} \mathrm{~cm}^{2} \text { per sec } \\
Q & =24,900 \mathrm{cal} \text { per mole }
\end{aligned}
$$

The se data are in good agreement with the data of Ang(13), who determined $Q$ as $27,600 \mathrm{cal}$ per mole and $D_{0}$ as $1.47 \times 10^{-2} \mathrm{~cm}^{2}$ per sec from internal friction measurements.

Using modification of Equation (3) it is possible to calculate fairly accurately the depth of contamination which will result from high-temperature exposure to oxygen or air. The modified equation is as follows:

$$
x=2 \sqrt{D t}\left[\phi^{-1}\left(1-\frac{\Delta H}{\frac{T}{4}+35}\right)\right],
$$

where

$$
\begin{aligned}
& T=\text { absolute temperature, } K \\
& \Delta H=\text { increase in Knoop hardness at distance } x \\
& \text { from the metal surface. } \\
& x, D, \text { and } t \text { are the same as in Equation(1). }
\end{aligned}
$$

The expression, $\Delta H / \frac{T}{4}+35$, is the ratio of the hardness increase to an empirical value for the maximum hardness, which is temperature dependent. Values of D can be calculated from the expression 




FIGURE 8. DEPTH OF CONTAMINATION FOR NIOBIUM OXIDIZED FOR 1, 5, AND $10 \mathrm{HR}$ AT VARIOUS TRMPERATURES

The criterion is a hardness increase of 50 Innoop points. 


$$
D=4.07 \times 10^{-3} e^{-24,900 / 1.987} \mathrm{~T}
$$

Several curves illustrating the use of Equation (5) are given in Figure 8. These curves show the depth of contamination for a hardness increase of 50 Knoop points for exposures of 1,5 , and $10 \mathrm{hr}$ at various temperatures. Similar curves can be plotted for other hardness increases and other exposure times.

\section{SUMMARY}

Niobium has been found to oxidize in a linear manner when exposed to 1 atm oxygen at 600 to $1200 \mathrm{C}$. From 600 to $1100 \mathrm{C}$, the activation energy was $5,410 \mathrm{cal}$ per mole; above $1100 \mathrm{C}$, the reaction proceeded more rapidly. At $1400 \mathrm{C}$ the oxidation reaction is exothermic. The oxide formed at all temperatures consisted of a thin black subscale of oriented $\mathrm{Nb}_{2} \mathrm{O}_{5}$ and $\mathrm{NbO}$, and an outer layer of white, porous $\mathrm{Nb}_{2} \mathrm{O}_{5}$. At $800 \mathrm{C}$ and 0.1 atm of oxygen, the reaction was parabolic.

The reaction between niobium and nitrogen is very slow up to $1000 \mathrm{C}$.

The reaction between niobium and undried air proceeds at a linear rate, although slower than the reaction with oxygen. The reaction rate at $1000 \mathrm{C}$ was lower than would be expected from the lower temperature rates. This may be a result of moisture in the air, or sintering of the oxide to produce a more protective scale. Heat of activation for air oxidation was $10,100 \mathrm{cal}$ per mole in the range 600 to $1200 \mathrm{C}$.

Contamination in the air-reacted and oxygen-reacted samples was attributed to oxygen diffusion, with a negligible contribution from nitrogen diffusion. Diffusion coefficients for oxygen in niobium were calculated from the contamination data, and a value of 24,900 cal per mole obtained for the activation energy for diffusion. Variations in the oxygen pressure by a factor of 10 did not affect the rate of diffusion of oxygen into niobium, indicating that the oxygen diffuses into the metal surface from the adherent subscale layer.

\section{REFERENCES}

(1) Orr, R. L., and Bainbridge, D. W., "The Correlation of HighTemperature Rupture Data for Niobium", Institute of Engineering Research Report, University of California, Berkeley, Series 22, Issue 28 (July 1, 1953). 
(2) Cross, H. C., and Simmons, W. F., "Alloys and Their Properties for Elevated Temperature Service", Utilization of Heat-Resistant Alloys, ASM (1954).

(3) Saller, H. A., Stacy, J. T., and Porembka, S. W. "Initial Investigation of Niobium and Niobium-Base Alloys", BMI-1003 (May 23, 1955).

(4) Sims, C. T., Klopp, W. D., and Jaffee, R. I., "Effects of Alloying Additions on the Oxidation of Niobium", to be published.

(5) Braver, G., Z. anorg. u, allgem. Chem., 248, 1-31 (1941).

(6) Zachariasen, W. H., Physics Report, CF-2926, 11 (April 15, 1945) (Confidential).

(7) Gulbransen, E.A., and Andrew, K. F., "Kinetics of the Reactions of Columbium and Tantalum with $\mathrm{O}_{2}, \mathrm{~N}_{2}$, and $\mathrm{H}_{2}^{\prime \prime}, \mathrm{J}$. Metals, 188, 586 (Max ch, 1950).

(8) Inouye, H., "Scaling of Columbium in Air", paper presented at Am. Inst. Mining Met. Eng. Reactive Metal Conf., Buffalo, New York (March 19-21, 1956).

(9) Belle, J. and Mallett, M.W., J. Electrochem. Soc, 101, 339 (1954).

(10) Durbin, E. A., Wagner, J. E., and Harman, C. G., "Properties of Some Columbium Oxide-Basic Ceramics", BMI-792 (December 15, 1952).

(11) Van Ostrand, C. E., and Dewey, F.P., U. S. Geological Survey, Prof. Paper $45 \mathrm{G}, 83$ (1915).

(12) Seybolt, A. U., "Solid Solubility of Oxygen in Columbium", J. Metals, 200, 774 (June, 1954 ).

(13) Ang, C. Y., "Activation Energies and Diffusion Coefficients of Oxygen and Nitrogen in Niobium and Tantalum", Acta Metallurgica, 1, 123 (March, 1953). 